\title{
Paper denying HIV-AIDS link secures publication
}

\section{Work by infamous AIDS contrarian passes peer review.}

\section{Zoë Corbyn}

05 January 2012

A controversial research paper that argued "there is as yet no proof that HIV causes AIDS" and met with a storm of protest when it was published in 2009 , leading to its withdrawal, has been republished in a revised form, this time in the peer-reviewed literature.

The reworked version of the paper, led by Peter Duesberg of the University of California, Berkeley, who is well known for denying the link between HIV and AIDS, was published in the Italian Journal of Anatomy and Embryology (IJAE) last month ${ }^{1}$.

The manuscript was examined by two peer reviewers, one of them the journal's editor-in-chief, Paolo Romagnoli, an expert in cell anatomy at the University of Florence, Italy. But leading AIDS researchers and campaigners question how the paper could have passed peer review, and say that publishing it in a minor journal known to few does not give it scientific credibility or legitimacy.

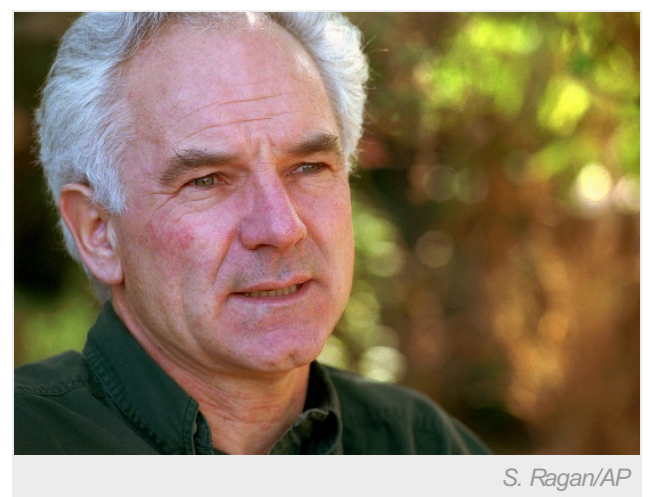

Peter Duesberg has for more than 20 years challenged the idea that HIV causes AIDS.

"In my view this paper is scientific nonsense and should not have passed peer review. The thesis that HIV does not cause AIDS has no scientific credibility," says Nathan Geffen of the South Africa-based Treatment Action Campaign, who previously raised concerns about the article.

Romagnoli says he decided to review the revised paper because the original was withdrawn by Medical Hypotheses not for "flawed or falsified data" but for "highly controversial opinions" — which the IJAEs readers can make up their own minds about.

"Speculative conclusions are not a reason for rejection, provided they are correlated with the data presented," he says.

\section{Potentially damaging}

The paper's initial publication in Medical Hypotheses caused a furore, with attention being drawn to the fact that the journal was not peer reviewed despite being listed in the MEDLINE citation database.

Retrospective peer review later led to the paper's permanent withdrawal from Medical Hypotheses. The grounds stipulated in the withdrawal notice were concerns over the paper's quality and that it contained opinions about the causes of AIDS "that could potentially be damaging to global public health" 2 .

The journal's publisher, Elsevier, revamped Medical Hypotheses to introduce peer review and fired editor Bruce Charlton, who resisted the changes. The University of California also bought charges of misconduct against Duesberg over the article's publication, but he was later cleared.

Duesberg says that the revised publication is a "new victory in our long quest for a scientific theory of AIDS", adding that the new version of the paper was better documented and more up to date.

Although the revised version has been toned down, the article still makes many of the same points as the original — refuting the effectiveness of anti-retroviral drugs, as well as death-toll estimates from HIV and AIDS in South Africa put forward in a study led by AIDS epidemiologist Max Essex of Harvard University in Boston, Massachusetts ${ }^{3}$. "We deduce ... that HIV is not a new killer virus," Duesberg et al. write, proposing a "reevaluation of the HIV-AIDS hypothesis".

But Geffen says the paper "contains no new arguments or evidence about the South African data, and these arguments have been rebutted before". 
Duesberg admits submitting the revised paper to more than four other journals before it was accepted by the IJAE, and only alerted his co-authors to the publication after he was sure it wouldn't be aborted at the last minute.

\section{Dangerous distraction}

"It is just so far out that it is hard to respond in an intelligent way," says Essex, adding that it is "unfortunate" to see Duesberg continuing on a "dangerous track of distraction that has persuaded some people to avoid treatment or prevention of HIV infection".

Yet whether the publication will be officially challenged remains to be seen. John Moore, an HIV researcher at Cornell University in New York, who lodged a complaint with Elsevier when the original paper was published, believes that the movement to deny the link between HIV and AIDS is on its "last legs". Geffen, meanwhile, thinks the likelihood the paper will have significant impact — and therefore warrant challenge - is small.

"Duesberg's views no longer have significant political support, like they did in South Africa in the 2000s," Geffen says. "No one of consequence in government is likely to take any notice."

Nature I doi:10.1038/nature.2012.9737

\section{References}

1. Duesberg, P. H. et al. Ital. J. Anat. Embryol. 116, 73-92 (2011).

2. http://www.ncbi.nlm.nih.gov/pubmed/19619953

3. Chigwedere, P. et al. J Acquir. Immune Defic. Syndr. 49, 410-415 (2008). 